\title{
EDUKASI KESEHATAN PADA REMAJA DALAM PENTINGNYA GIZI SEIMBANG DAN AKTIVITAS FISIK DI ERA PANDEMI COVID-19
}

\author{
Romaden Marbun"1), Sugiyanto'), Vincensia Dea') \\ 1)Program Studi Sarjana Terapan Manajemen Informasi Kesehatan, STIKes Panti Waluya Malang, Malang, Jawa Timur \\ Corresponding author : Vincensia Dea \\ E-mail : vincensiadhea@yahoo.com
}

\section{Diterima 12 April 2021, Direvisi 29 April 2021, Disetujui 01 Mei 2021}

\begin{abstract}
ABSTRAK
Pandemi COVID-19 di Indonesia sangat memberikan dampak pada berbagai sektor di seluruh dunia, tidak terkecuali kenaikan frekuensi Penyakit Tidak Menular. Penyakit tidak menular (PTM) adalah penyakit atau kondisi medis yang tidak dapat ditularkan dari satu individu ke individu lainnya atau dengan pengertian lain merupakan penyakit yang bukan disebabkan oleh proses infeksi (tidak infeksius). Masalah gizi lebih atau obesitas merupakan masalah global dan menjadi masalah utama di negaranegara maju dan berkembang karena mengalami peningkatan tiap tahun yang berkaitan dengan penyakit tidak menular. Dari survei awal diketahui pengetahuan para remaja masih kurang terkait Pentingnya Gizi Seimbang dan Aktivitas Fisik Dalam Upaya Pencegahan Penyakit Tidak Menular (PTM) . Tujuan dilakukannya kegiatan ini adalah untuk meningkatkan keselamatan para remaja dalam masalah gizi dan penyakit tidak menular khususnya di era pandemi covid-19 sekarang. Kegiatan ini dikemas dalam bentuk pemberian materi dan video tentang Pentingnya Gizi Seimbang dan Aktivitas Fisik Dalam Upaya Pencegahan Penyakit Tidak Menular (PTM) di Era Pandemi Covid-19 . Disetiap akhir kegiatan dilakukan evaluasi terhadap pemahaman remaja. Hasil dari kegiatan pengabdian kepada masyarakat terdapat sebanyak $68 \%$ pemahaman remaja dalam katergori baik, cukup sebanyak $20 \%$ dan kurang sebanyak $12 \%$. Kegiatan berjalan dengan baik dan perlu adanya monitoring lebih lanjut.
\end{abstract}

Kata kunci: Penyakit Tidak Menular (PTM); gizi seimbang; aktivitas fisik; covid-19

\begin{abstract}
The COVID-19 pandemic in Indonesia has had a profound impact on various sectors around the world, including the increase in the frequency of Non-Communicable Diseases. Non-communicable disease (PTM) is a disease or medical condition that cannot be transmitted from one individual to another or in other terms is a disease that is not caused by an infectious (non-infectious) process. The problem of over nutrition or obesity is a global problem and is a major problem in developed and developing countries because it has increased every year related to non-communicable diseases. From the initial survey, it was found that teenagers' knowledge was still lacking regarding the importance of balanced nutrition and physical activity in preventing non-communicable diseases (PTM). The purpose of this activity is to improve the safety of adolescents in nutrition and non-communicable diseases, especially in the current Covid-19 pandemic era. This activity is packaged in the form of providing materials and videos about the Importance of Balanced Nutrition and Physical Activity in Efforts to Prevent NonCommunicable Diseases (PTM) in the Covid-19 Pandemic Era. At the end of each activity, an evaluation of the understanding of adolescents is carried out. The results of community service activities were as much as $68 \%$ of the residents' understanding was in the good category, $20 \%$ enough and $12 \%$ less. Activities are running well and further monitoring is needed.
\end{abstract}

Keywords: Non-Communicable Diseases (PTM); balanced nutrition; physical activity; covid-19

\section{PENDAHULUAN}

Penyakit Tidak Menular (PTM) sudah menjadi masalah kesehatan masyarakat secara global, regional, nasional dan lokal terlebih pada era Pandemi Covid-19 baru-baru ini. Pandemi COVID-19 di Indonesia sangat memberikan dampak pada berbagai sektor di seluruh dunia, tidak terkecuali kenaikan frekuensi Penyakit Tidak Menular. Penyakit tidak menular (PTM) adalah penyakit atau kondisi medis yang tidak dapat ditularkan dari satu individu ke individu lainnya atau dengan pengertian lain merupakan penyakit yang bukan disebabkan oleh proses infeksi (tidak infeksius). Mayoritas PTM terjadi di negara berpendapatan rendah dan menengah. Meningkatnya kasus Penyakit Tidak Menular (PTM) secara signifikan akan menambah 
beban masyarakat dan pemerintah, karena penanganannya membutuhkan waktu yang tidak sebentar, biaya yang besar dan teknologi tinggi. Pada tahun 2016, sekitar 71 persen penyebab kematian di dunia adalah penyakit tidak menular (PTM) yang membunuh 36 juta jiwa per tahun. Sekitar 80 persen kematian tersebut terjadi di negara berpenghasilan menengah dan rendah. $73 \%$ kematian saat ini disebabkan oleh penyakit tidak menular, 35\% diantaranya karena penyakit jantung dan pembuluh darah, $12 \%$ oleh penyakit kanker, $6 \%$ oleh penyakit pernapasan kronis, 6\% karena diabetes, dan $15 \%$ disebabkan oleh PTM lainnya (World Health Organization, 2018).

Keberadaan faktor resiko PTM pada seseorang tidak memberikan gejala sehingga mereka tidak merasa perlu mengatasi faktor resiko dan mengubah gaya hidupnya. Masyarakat pada umumnya mengetahui jenisjenis PTM namun tidak mengetahui pengaruh faktor resiko PTM terhadap kejadian PTM serta kompilasi yang dapat ditimbulkan PTM. Masyarakat menganggap bahwa PTM disebabkan oleh faktor genetik, penyakit orangtua atau penyakit orang kaya sehingga pada umumnya mreka datang dalam keadaan sudah parah dan tidak tertangani dengan baik.

Masalah gizi lebih atau obesitas merupakan masalah global dan menjadi masalah utama di negara-negara maju dan berkembang karena mengalami peningkatan tiap tahun. Obesitas merupakan masalah karena lemak yang terdapat di dalam tubuh mengalami kelebihan, hal ini akan berdampak negatif pada kesehatan masyarakat. Berdasarkan data dari WHO tahun 2010 prevalensi obesitas dari tahun 1990 sebesar $4,2 \%$, pada tahun 2010 meningkat menjadi $6,7 \%$ (World Health Organization, 2015). Di Indonesia, masalah gizi lebih atau obesitas juga mengalami peningkatan setiap tahunnya. Data Riset Kesehatan Dasar, pada tahun 2007 sebesar 10.5\%, tahun 2013 persentase sebensar $14.8 \%$, dan 2018 persentase sebesar $21.8 \%$. Khususnya kondisi obesitas sentral pada usia $>12$ tahun terdapat $18.8 \% \%$ tahun 2007, sebesar $26.6 \%$ tahun 2013 dan 31.0\% pada tahun 2018. Kondisi ini dapat dialami oleh setiap golongan usia, baik laki-laki maupun perempuan (Kementerian Kesehatan RI, 2018).

Masalah obesitas bagi usia remaja dapat menyebabkan berbagai macam penyakit tidak menular, seperti stroke, jantung, dan diabetes melitus tipe 2 yang merupakan penyebab utama kematian di tahun 2012. Namun, tidak hanya itu beberapa penyakit lainnya seperti muskuloskeletal (osteoatritis, cidera) dan beberapa jenis kanker termasuk endometrium, payudara, ovarium, prostat, hati, kandung empedu, ginjal dan usus besar (Twig et al., 2016).

Penilaian status gizi merupakan kondisi keseimbangan antara asupan dan kebutuhan zat gizi yang diperlukan tubuh untuk tumbuh kembang terutama untuk anak sampai usia dewasa, aktifitas, pemeliharan kesehatan, penyembuhan bagi mereka yang menderita sakit dan proses biologis lainnya di dalam tubuh agar bisa hidup sehat dan produktif. Status gizi yang baik akan turut berperan dalam pencegahan terjadinya berbagai penyakit, khususnya penyakit infeksi dan dalam tercapainya tumbuh kembang anak yang optimal (Priyo, Titus H.; Par'i, Holil M; Wiyowo, 2017)

Pada remaja, kejadian kegemukan dan obesitas merupakan masalah yang serius karena akan berlanjut hingga usia dewasa. Masalah obesitas pada dewasa ini merupakan faktor risiko terjadinya berbagai penyakit metabolik dan degeneratif seperti penyakit kardiovaskuler, diabetes mellitus, kanker, osteoartritis, dan lain-lain. Pada anak usia 1318 tahun, kegemukan dan obesitas juga dapat mengakibatkan berbagai masalah kesehatan yang sangat merugikan kualitas hidup anak seperti gangguan pertumbuhan tungkai kaki, gangguan tidur, sleep apnea (henti napas sesaat) dan gangguan pernafasan lainnya (Ali, Onibala, \& Bataha, 2017). Edukasi Kesehatan dirasa sangat diperlukan terutama kegiatan yang berhubungan dengan pentingnya gizi seimbang dan aktivitas fisik yang perlu dilakukan di era pandemi covid-19 ini.

Sehubungan dengan permasalahan tersebut, pihak STIKes Panti Waluya Malang melaksanakan kegiatan pengabdian kepada masyarakat dalam memberikan pembinaan, pendampingan dan konsultasi bagi remaja terkait Pentingnya Gizi Seimbang dan Aktivitas Fisik Dalam Upaya Pencegahan Penyakit Tidak Menular (PTM) Pada Remaja di Era Pandemi Covid-19 sehingga terwujud generasi bangsa yang maju dan berdayaguna.

\section{METODE}

Kegiatan Pengabdian kepada Masyarakat (PKM) ini dilakukan di RT 09 RW 05 Kelurahan Bandulan, Kecamatan Sukun, Kota Malang dengan sasaran para remaja khususnya remaja karang taruna yang berjumlah 25 orang. Pelaksanaan pengabdian dilakukan 3 kali. Metode pelaksanaan yang diterapkan untuk mencapai tujuan dari program kemitraan ini adalah dimulai dari tahap persiapan, tahap pelaksanaan dan tahap evaluasi.

Tahapan persiapan dilakukan dengan pendekatan kepada para tokoh yang terlibat 
mulai dari mengurus birokrasi dan permohonan ijin kepada pihak terkait, pertemuan dengan tokoh masyarakat dan ketua karang taruna, mengobservasi masalah kesehatan sesuai dengan topik yang diambil lalu merencanakan waktu kegiatan bersama. Dengan ditetapkan bentuk kegiatan secara daring mengingat himbauan pemerintah terkait PPKM Mikro di era pandemi covid-19 untuk meminimalkan kegiatan berkumpul.

Tahapan Pelaksanaan dilakukan dengan melakukan sosialisasi kepada remaja karang taruna mengenai Pentingnya Gizi Seimbang dan Aktivitas Fisik Dalam Upaya Pencegahan Penyakit Tidak Menular (PTM) di Era Pandemi Covid-19 yang dilakukan dalam bentuk pemberian materi dan video edukasi yang dibuat untuk menunjang pengetahuan terkait topik yang dilakukan. Pemberian materi, tanya jawab dan diskusi interaktif dilakukan secara daring melalui grup whatsapp.

Tahapan Evaluasi atas program yang telah dilaksanakan meliputi telah terlaksananya Pentingnya Gizi Seimbang dan Aktivitas Fisik Dalam Upaya Pencegahan Penyakit Tidak Menular (PTM) Pada Remaja di Era Pandemi Covid-19. Evaluasi dilakukan terhadap respon para remaja baik melalui pertanyaan pretest dan post-test terkait materi penyuluhan. Tahap evaluasi dilakukan melalui google form terhadap reakasi warga dalam pemahaman materi yang disampaikan melalui media pembelajaran yang disampaikan.

\section{HASIL DAN PEMBAHASAN}

Program pengabdian kepada masyarakat (PKM) yang dilaksanakan di RT 09 RW 05 Kelurahan Bandulan, Kecamatan Sukun, Kota Malang ini mendapat kan respon yang positif dari tokoh masyarakat yaitu perangkat desa serta masyarakat dan terkhusus para remaja karang taruna. Sasaran utama program ini adalah para remaja yang tergabung dalam kelompok karang taruna di RT 09 RW 05 Kelurahan Bandulan, Kecamatan Sukun, Kota Malang berjumlah 25 orang. Pra kegiatan ini dilaksanakan pada tanggal 5 Januari 2021 secara daring melalui grup whatsapp dan didapatkan distribusi frekuensi peserta PKM yang merupakan anggota karang taruna (Tabel 1) serta diketahui bahwa para remaja juga minim pengetahuan tentang gizi seimbang dan kurang melakukan aktivitas fisik saat mereka melakukan pembelajaran daring di rumah selama pandemi covid-19.

Tabel 1. Distribus Frekuensi peserta PKM

\section{KATEGORI FREK. PERSENTASE}

\begin{tabular}{lcc}
\hline \multicolumn{3}{c}{ JENIS KELAMIN } \\
\hline LAKI-LAKI & 12 & $48 \%$ \\
\hline PEREMPUAN & 13 & $52 \%$ \\
\hline
\end{tabular}

\begin{tabular}{lcc}
\hline TOTAL & $\mathbf{2 5}$ & $\mathbf{1 0 0} \%$ \\
\hline & USIA & \\
\hline SMA & 12 & $48 \%$ \\
\hline PERGURUAN & 9 & $36 \%$ \\
TINGGI & & \\
\hline BEKERJA & 4 & $16 \%$ \\
\hline TOTAL & $\mathbf{2 5}$ & $\mathbf{1 0 0} \%$ \\
\hline
\end{tabular}

Pelaksanaan kegiatan pengabdian kepada masyarakat dilaksanakan sebanyak 2 (dua) kali yaitu tanggal 10 Januari 2021 dan 17 Januari 2021 secara daring dengan metode penyuluhan dan diskusi interaktif melalui grup diskusi whatsapp. Materi penyuluhan terbagi menjadi 2 bagian. Materi pertama berisi tentang Pentingnya Gizi Seimbang meliputi definisi gizi seimbang, pilar gizi seimbang, tumpeng gizi dan piring makanku, dan kaitan antara gizi seimbang dengan PTM dan materi kedua berisi tentang Aktivitas Fisik Dalam Upaya Pencegahan Penyakit Tidak Menular (PTM) meliputi definisi, manfaat melakukan aktivitas fisik dan juga gerakan ringan (stretching) yang bisa dilakukan dan kaitan antara aktivitas fisik dan PTM yang ditampilkan dalam bentuk poster penyuluhan dan dipaparkan pada saat penyuluhan seperti gambar 1 .

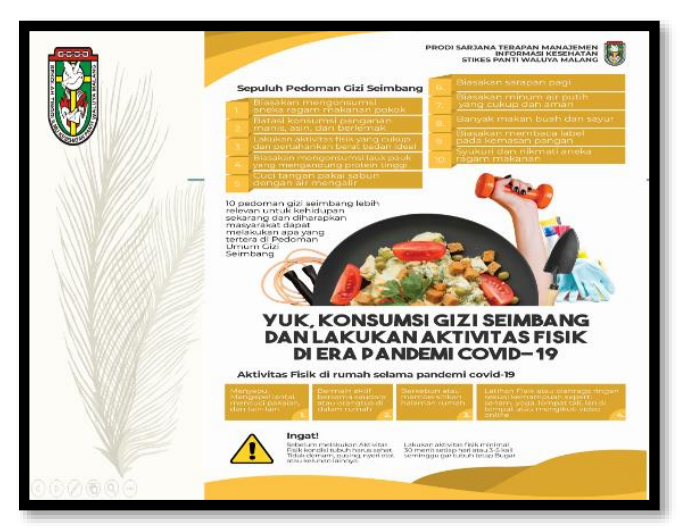

Gambar 1. Poster materi penyuluhan

Sebelum dilaksanakan kegiatan penyuluhan, terlebih dahulu peserta dilakukan pretest guna menilai tingkat pemahaman peserta terkait topik yang diberikan. Setelah diberikan penyuluhan sebanyak 2 kali dengan jarak 1 minggu, para peserta kembali diberikan post-test guna menilai adanya peningkatan pemahaman atau tidak para sasaran penyuluhan. 
Tabel 1. Distribus Frekuensi peserta PKM berdasarkan Pemahaman materi

\begin{tabular}{lcc}
\hline PEMAHAMAN & FREK & PERSENTASE \\
\hline Baik & 17 & $68 \%$ \\
\hline Cukup & 5 & $20 \%$ \\
\hline Kurang & 3 & $12 \%$ \\
\hline \multicolumn{1}{c}{ TOTAL } & $\mathbf{2 5}$ & $\mathbf{1 0 0} \%$ \\
\hline
\end{tabular}

Dari hasil evaluasi yang diberikan di akhir kegiatan, didapatkan hasil pemahaman materi yang diterima oleh para remaja di kelompok karang taruna RT 09 RW 05 Baik dengan persentase $68 \%$ dengan artian mereka mampu menerima pemberian materi terkait Pentingnya Gizi Seimbang dan Aktivitas Fisik Dalam Upaya Pencegahan Penyakit Tidak Menular (PTM) dan diharapkan kegiatan dengan topik seperti ini giat dilakukan dan melalui video pembelajaran yang berupa senam Gizi Seimbang dapat dilakukan individu di rumah secara rutin dan dilakukan monitoring lanjutan.

Pada fase remaja merupakan fase yang banyak mengalami perubahan gaya hidup dan kebiasaan makan. Adanya faktor lingkungan menyebabkan perbedaan preferensi makan, khususnya bagi anak perempuan. Sebagian besar remaja yang mengikuti kegiatan edukasi ini berjenis kelamin perempuan. Komposisi tubuh berdasarkan perbedaan jenis kelamin, kriteria persen lemak tubuh pada perempuan lebih tinggi karena perbedaan hormon dan juga perempuan dipersiapkan menjadi calon ibu. Sehingga pemberian edukasi gizi yang paling cepat berpengaruh terhadap perubahan sikap dan prilaku adalah saat masa remaja. Salah satu poin dalam edukasi gizi ini mengetahui porsi makan melalui tumpeng gizi seimbang dan piring makanku.

Perlunya setiap remaja mengetahui karakteristik, inovasi dan kebaragaman dari menu gizi seimbang agar yang dikonsumsi sesuai dengan kebutuhan karena perkembangan zaman yang sangat dinamis berdampak pada perubahna pola konsumsi makan. Pada masa remaja ini keingintahuan dari berbagai jenis makanan dan minuman yang trend ingin dicoba untuk dikonsumsi. Harapanya setelah pemberian edukasi ini para remaja di karang taruna $R T 09$ lebih kritis dan paham jenis bahan makanan yang baik untuk kesehatan berdasarkan komposisi bahan makanan.

Upaya perbaikan status gizi lebih optimal yaitu dengan kombinasi konseling gizi dan program latihan streching efektif dalam perbaikan status gizi (Gifari, Kuswari, \& Azza, 2018). Remaja yang memiliki asupan zat gizi makro berlebih, frekuensi konsumsi fast food sering, aktivitas fisik tidak aktif, memiliki ibu dan ayah dengan status obesitas, serta tidak sarapan, berisiko lebih terhadap terjadinya obesitas (Kurdanti et al., 2015)(Thaddanee, Chaudhari, Thakor, Thaddanee, \& Pediatr, 2016). Dengan adanya edukasi gizi seimbang dan aktivitas fisik secara terus menerus diharapkan dapat menigkatkan pengetahuan gizi dan juga perbaikan perilaku menjadi lebih baik.

\section{SIMPULAN DAN SARAN}

Pengabdian kepada Masyarakat mengenai Pentingnya Gizi Seimbang dan Aktivitas Fisik Dalam Upaya Pencegahan Penyakit Tidak Menular (PTM) Pada Remaja di Era Pandemi Covid-19 ini telah terlaksana dengan baik secara daring dengan pemberian materi , diskusi dan tanya jawab interaktif, serta pemberian video edukasi guna menunjang topik yang dilaksanakan. Hasil yang didapatkan juga bahwa pengetahuan para remaja khususnya remaja karang taruna meningkat dan para remaja lebih mengerti mengenai Gizi Seimbang dan Aktivitas Fisik Dalam Upaya Pencegahan Penyakit Tidak Menular (PTM). Diharapkan dengan adanya peningkatan pengetahuan ini, para remaja lebih memahami tentang gizi dan aktivitas fisik guna mencegah penyakit tidak menular yang dapat dilakukan di era pandemi covid-19 ini.

\section{UCAPAN TERIMAKASIH}

Pengabdi mengucapkan terima kasih kepada Ketua dan warga RT 09 RW 05 Kel. Bandulan Kec. Sukun Kota Malang yang bersedia menjadi subjek binaan dalam pengabdian kepada masyarakat ini. Tidak lupa pula pengabdi mengucapkan terima kasih kepada STIKes Panti Waluya Malang yang membiayai kegiatan pengabdian kepada masyarakat ini.

\section{DAFTAR RUJUKAN}

Ali, W., Onibala, F., \& Bataha, Y. (2017). Perbedaan Anak Usia Remaja Yang Obesitas Dan Tidak Obesitas Terhadap Kualitas Tidur Di Smp Negeri 8 Manado. Jurnal Keperawatan UNSRAT, 5(1), 114296.

Gifari, N., Kuswari, M., \& Azza, D. (2018). Pengaruh Konseling Gizi Dan Latihan Stretching Terhadap Perubahan Asupan Gizi Dan Status Gizi ( Effect of Nutritional Counseling and Stretching Exercises Programs on Nutritional Status and Nutrition Intake ), 2(1), 2940.

Kementerian Kesehatan RI. (2018). Laporan Riskesdas 2018. Laporan Nasional 
Riskesdas 2018 (Vol. 53). Jakarta: Badan Penelitian dan Pengembangan Kesehatan (LPB). Retrieved from http://www.yankes.kemkes.go.id/asset s/downloads/PMK No. 57 Tahun 2013 tentang PTRM.pdf

Kurdanti, W., Suryani, I., Syamsiatun, N. H., Siwi, L. P., Adityanti, M. M., Mustikaningsih, D., \& Sholihah, K. I. (2015). Faktor-faktor yang mempengaruhi kejadian obesitas pada remaja. Jurnal Gizi Klinik Indonesia, 11(4), 179. https://doi.org/10.22146/ijen.22900

Priyo, Titus H.; Par'i, Holil M; Wiyowo, S. (2017). Penilaian Status Gizi. Badan Pengembangan dan Pemberdayaan Sumber Daya Manusia Kesehatan. Retrieved from www.bppsdmk.kemkes.go.id

Thaddanee, R., Chaudhari, U. R., Thakor, N., Thaddanee, R., \& Pediatr, J. C. (2016). Prevalence and determinants of obesity and overweight among school children of Ahmedabad City, Gujarat: a cross sectional study, 3(2), 606-611.

Twig, G., Yaniv, G., Levine, H., Leiba, A., Goldberger, N., Derazne, E., ... Kark, J. D. (2016). Body-Mass Index in 2.3 Million Adolescents and Cardiovascular Death in Adulthood. New England Journal of Medicine, 374(25), 24302440.

https://doi.org/10.1056/nejmoa150384 0

World Health Organization. (2015). World Health Statistics 2015. Luxembourg: World Health Organization. Retrieved from https://www.who.int/docs/defaultsource/gho-documents/world-healthstatistic-reports/world-health-statistics2015.pdf

World Health Organization. (2018). Noncommunicable diseases country profiles 2018. Switzerland: World Health Organization. Retrieved from https://www.who.int/nmh/publications/n cd-profiles-2018/en/ 